\title{
Influence of Waste Brick Powder in the Mechanical Properties of Recycled Aggregate Concrete
}

\author{
Viviana Letelier ${ }^{1}$, José Marcos Ortega ${ }^{2, *(1)}$, Pedro Muñoz ${ }^{3}$, Ester Tarela ${ }^{1}$ and \\ Giacomo Moriconi ${ }^{4}$ \\ 1 Departamento de Obras Civiles, Universidad de la Frontera, Av. Fco. Salazar, Temuco 01145, Chile; \\ viviana.letelier@ufrontera.cl (V.L.); ester.tarela@ufrontera.cl (E.T.) \\ 2 Departamento de Ingeniería Civil, Universidad de Alicante, Ap. Correos 99, 03080 Alacant/Alicante, Spain \\ 3 Escuela Superior de Ingeniería y Tecnología (ESIT), Universidad Internacional de La Rioja, Av. de la Paz, 137, \\ 26006 Logroño, La Rioja, Spain; pedro.munoz@unir.net \\ 4 Department of Science and Engineering of Matter, Environment and Urban Planning, \\ Università Politecnica delle Marche, Via Brecce Bianche, 60131 Ancona, Italy; g.moriconi@univpm.it \\ * Correspondence: jm.ortega@ua.es; Tel.: +34-96-5903-400 (ext. 1167)
}

Received: 9 March 2018; Accepted: 28 March 2018; Published: 31 March 2018

check for updates

\begin{abstract}
Brick and concrete are the main materials contributing to demolition and construction waste. Considering this precedent, the effects of using both residuals in medium strength concretes are analyzed. Waste brick powder is used as a cement replacement in three different levels: $5 \%$, $10 \%$, and $15 \%$, and it is tested in concretes with no recycled aggregates and concretes with $30 \%$ of recycled coarse aggregates replacing natural ones. The compressive strength, the flexural strength, and modulus of elasticity are calculated and compared to a control concrete with no brick powder and no recycled aggregates. The effects of the simultaneous use of both residuals on the physical properties of the recycled concrete are highlighted. Results show that $15 \%$ of cement can be replaced by waste brick powder together with $30 \%$ of recycled aggregates without suffering significant losses in the strength of the final material when compared to a control concrete.
\end{abstract}

Keywords: waste brick powder; recycled aggregates; eco-materials; compressive strength; flexural strength; Young's modulus

\section{Introduction}

Waste management has become an unavoidable social concern in modern societies [1-3]. In particular, the building sector provides up to $25 \%$ of the total solid waste disposal [4]. According to different researchers [5-7], ceramic materials (i.e., bricks and tiles) and concrete are the materials that contribute the most to construction and demolition waste (CDW). In fact, several cities have reported that the brick residues reach $50 \%$ of the total CDW and the concrete ones reach around $12 \%$, making these cases especially concerning [5-7], and leading many researchers to analyze alternatives to reuse these materials by including them in the manufacture of new construction materials.

Even though the production of ordinary Portland cement (OPC) consumes significant amounts of energy and natural raw materials, it is widely used as a building material [8]. Furthermore, the cement industry is responsible for $5-7 \%$ of the worldwide $\mathrm{CO}_{2}$ emissions [9-11]. Partially replacing OPC with alternative recycled materials [12-15] can substantially reduce the environmental impact of cement production, and therefore, concrete production.

Clay brick powder $(\mathrm{CBP})$ is a suitable candidate to replace cement in concrete production due to its pozzolanic properties [16-18]. The manufacturing of clay brick implies an exposure to elevated temperatures, ranging from 600 to $1000{ }^{\circ} \mathrm{C}$, that cause a change in the structure of its silicates to 
an amorphous compound that reacts with lime at room temperature [19]. In addition to this, it is important to mention that there are several works $[20,21]$ in which the reuse of powder obtained from cement or mortar bricks has been studied. In this regard, the main difference in comparison with CBP is that for reusing the cement brick powder it is necessary to carry out a thermal treatment after crushing it, in order to rehydrate the cement particles for partially recovering their hydraulic and pozzolanic properties $[20,21]$.

Kulovaná et al. [22] studied concretes using up to $60 \%$ of CBP as a cement replacement for a water/cement ratio of 0.4 . Their conclusions show that replacing $20 \%$ of the cement does not compromise the mechanical and physical properties of the concretes, and furthermore, the use of this material improves the thermal conductivity by up to 50\%. Katzer [23] analyzed mortars with $10 \%$ to $50 \%$ cement replacement by CBP, concluding that these residuals can be used in concretes with low requirements (water/cement ratio of over 0.6). Lavat et al. [24] studied the use of roof tile waste, finding that if the material is properly ground, it can replace between $20 \%$ and $30 \%$ of the cement. Ge et al. [25] optimized the mix to enhance the mechanical properties of concretes using CBP. The optimal mix for compressive strength had a water/cement ratio of $0.26,33 \%$ of sand, maximum CBP particle size of $0.06 \mathrm{~mm}$, and $25 \%$ cement replacement by CBP. Ge et al. [26] analyzed the behavior of concretes with CBP cement replacements between $10 \%$ and $30 \%$ by CBPs with different particle size, concluding that the compressive strength decreases when the amount of CBP and its particle size increase. Gonçalves et al. [27] found that by replacing up to $20 \%$ of the cement by CBP, the hydrates formed by the pozzolanic reaction could maintain a constant compressive strength. However, if the amount of CBP replaced increased, the hydrates were not enough to maintain the compressive strength of the final material, and the unreacted CBP could only contribute to the strength because of its physical filler effect.

Schackow et al. [28] studied the durability of mortars using fired CBP. Results concerning compressive strength are encouraging, showing an increase in the strength with the use of up to $40 \%$ of CBP. They attributed these results to a reduction in the pore structure of the mortars due to CBP, due to the filler effect of the fine particles of CBP. Also, the amorphous compounds (silica, alumina, and calcium hydroxide) generate similar silicate/aluminate hydrates to the ones produced in cement hydrations, contributing to the strength increase.

On the other hand, the replacement of natural coarse aggregates by recycled aggregates (RA) in concrete manufacturing has been widely analyzed [29-31]. Researchers agree that the losses in strength provoked by the use of RA are mainly due to the old mortar that remains attached to their surfaces. When natural aggregates are used, a weak interface between them and the cement mixture has to be considered, but when the aggregates are reused, two interfaces may affect the strength of the material: one between the old mortar and the RA, and a new one between the RA (with the mortar) and the new cement mixture [30]. The amount of mortar and its quality determine the state of the weak zones, becoming a key factor in the strength of the recycled concrete [31,32]. A common way to control this effect is to limit the percentage of aggregates replaced. Authors [33-40] conclude that small amounts of RA do not have a significant effect in the mechanical properties of the recycled concrete, and nowadays, several European technical regulations have allowed the use of $30 \%$ of RA for structural concrete manufacturing.

The use of RA and CBP as replacements in construction materials has been widely studied separately, but their simultaneous use has not been tested yet. The goal of this research is to study the effect of both replacements-CBP as cement and RA as natural coarse aggregates-on compressive and flexural strength and Young's modulus, and to optimize the mixture, minimizing the strength losses while maximizing the amount of recycled materials involved.

This analysis is a complete study derived from the preliminary work by the same authors [41]. The results of the first analysis encouraged the authors to further study the reuse of this recycled material. 


\section{Methods and Materials}

\subsection{Cement and CBP}

The targeted compressive concrete strength after 28 curing days was set at $30 \mathrm{MPa}$.

CBP, obtained from industrial brick residuals from demolition debris, was used to replace different amounts of pozzolanic cement, equivalent to ASTM type P cement (pozzolanic cement used when high strength at early ages is not required). Particles under $75 \mu \mathrm{m}$ were selected after grinding and sieving the CBP. The results of the chemical and physical analysis are shown in Table 1.

Table 1. Physical and chemical properties of cement and clay brick powder (CBP).

\begin{tabular}{ccc}
\hline Composition & Cement & CBP \\
\hline $\mathrm{SiO}_{2}$ & $38.06 \%$ & $41.47 \%$ \\
$\mathrm{Al}_{2} \mathrm{O}_{3}$ & $8.88 \%$ & $39.05 \%$ \\
$\mathrm{CaO}$ & $40.92 \%$ & $0.63 \%$ \\
$\mathrm{Fe}_{2} \mathrm{O}_{3}$ & $2.83 \%$ & $12.73 \%$ \\
$\mathrm{SO}_{3}$ & $2.33 \%$ & $1.59 \%$ \\
$\mathrm{MgO}$ & $1.59 \%$ & - \\
$\mathrm{Na}_{2} \mathrm{O}$ & $1.75 \%$ & - \\
$\mathrm{K}_{2} \mathrm{O}$ & $1.62 \%$ & $2.81 \%$ \\
$\mathrm{TiO}_{2}$ & - & $1.03 \%$ \\
$\mathrm{CuO}$ & - & $0.70 \%$ \\
Density & $2688 \mathrm{~kg} / \mathrm{m}^{3}$ & $2660 \mathrm{~kg} / \mathrm{m}^{3}$ \\
Blaine surface area & $4610 \mathrm{~m}^{2} / \mathrm{kg}$ & $6485 \mathrm{~m}^{2} / \mathrm{kg}$ \\
\hline
\end{tabular}

Blaine values specified in Table 1 were obtained following the ASTM C204 specifications. The values show that CBP presents higher specific surface than cement, agreeing with previous studies [42].

The mineralogical study of the dry CBP was carried out using XRD. The inorganic crystalline phases identified in the XRD patterns (Figure 1) are silica (sand used to adjust the plasticity of the brick green mixture), illite (the main mineralogical constituent of the clay used in brick manufacture), and hematite (used to reduce the firing temperature and favor the formation of liquid phases).

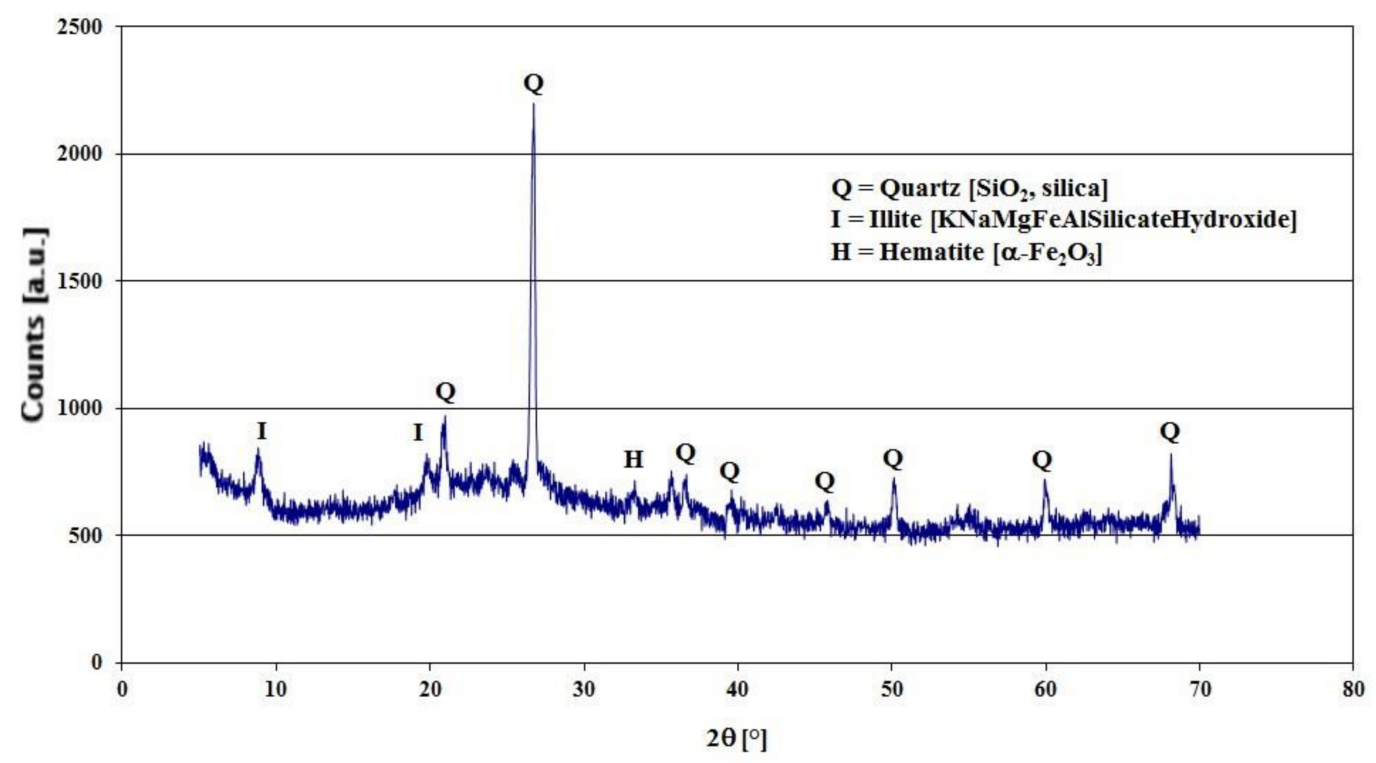

Figure 1. XRD pattern of CBP (the meaning of a.u. is arbitrary units). 
In Figure 2, a SEM observation is reported, showing that CBP consists of morphologically irregular particles, whilst the elemental analysis (Figure 3 ) is substantially consistent with the XRD analysis.

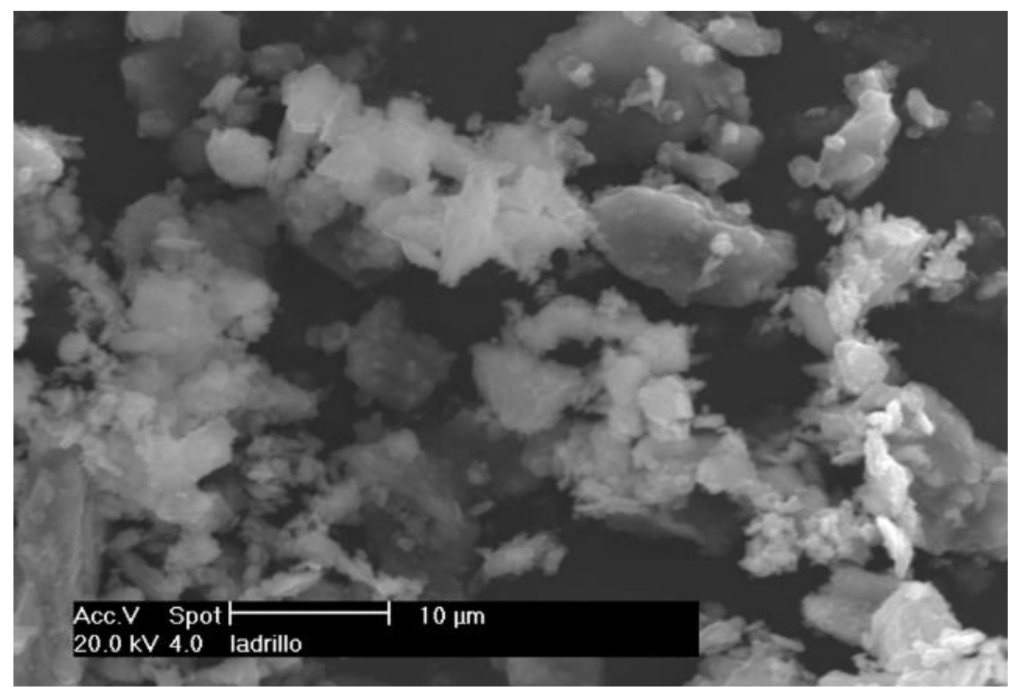

Figure 2. SEM micrograph of CBP.

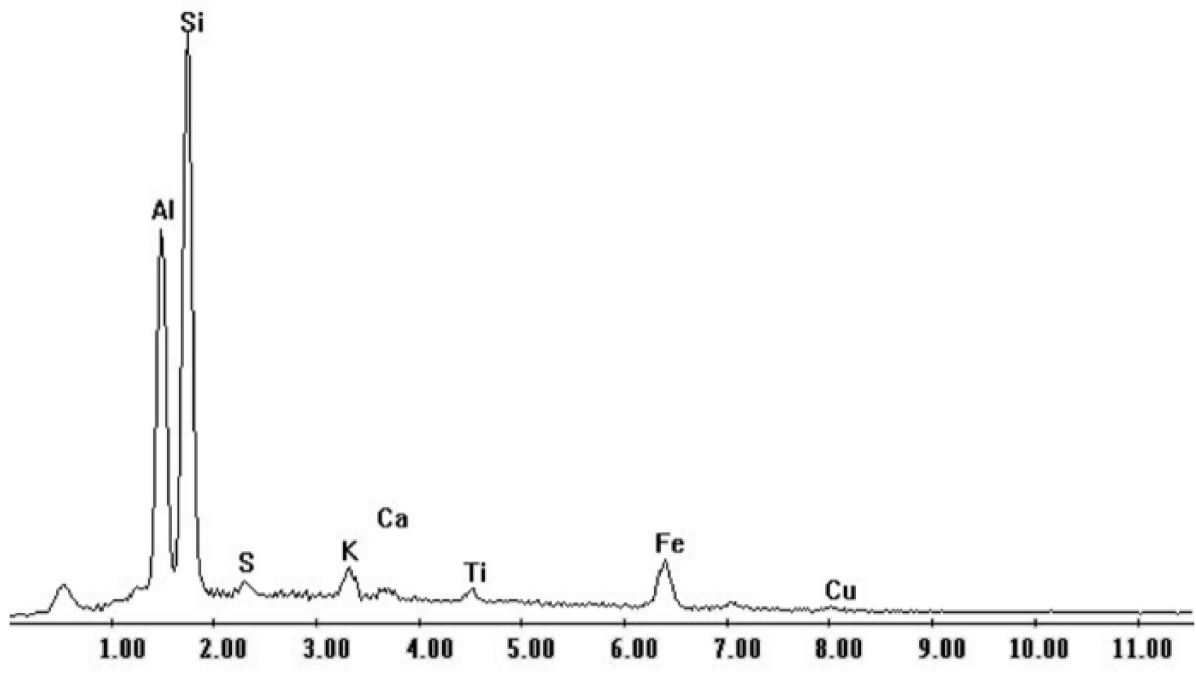

Figure 3. Energy dispersive X-ray spectroscopy (EDS) analysis of CBP.

Figure 4 shows the particle size distribution of the CBP used. 


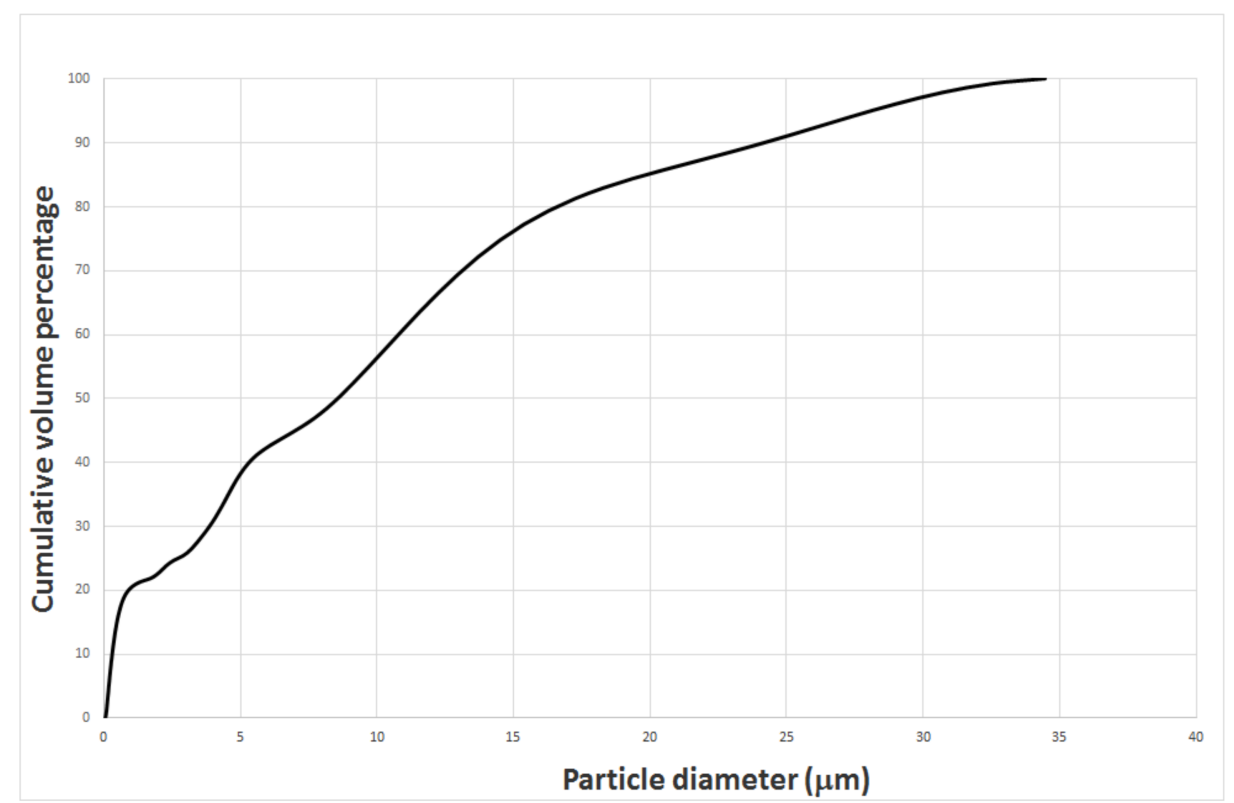

Figure 4. Particle size distribution of CBP.

\subsection{Natural and Recycled Aggregates}

Precast concrete debris with an original compressive strength of around $17 \mathrm{MPa}$ was used to obtain the RA. The nominal sizes considered were $12.5 \mathrm{~mm}, 9.5 \mathrm{~mm}$, and $6.3 \mathrm{~mm}$.

A thermal treatment has been used before $[43,44]$ to measure the amount of mortar adhered to the aggregate surfaces. A thermal shock is applied to the RA, eliminating the remaining mortar. Figure 5 shows the results. In all cases, the percentages of mortar attached to each of the RA are over $50 \%$, and they decrease as the size of the RA increases.

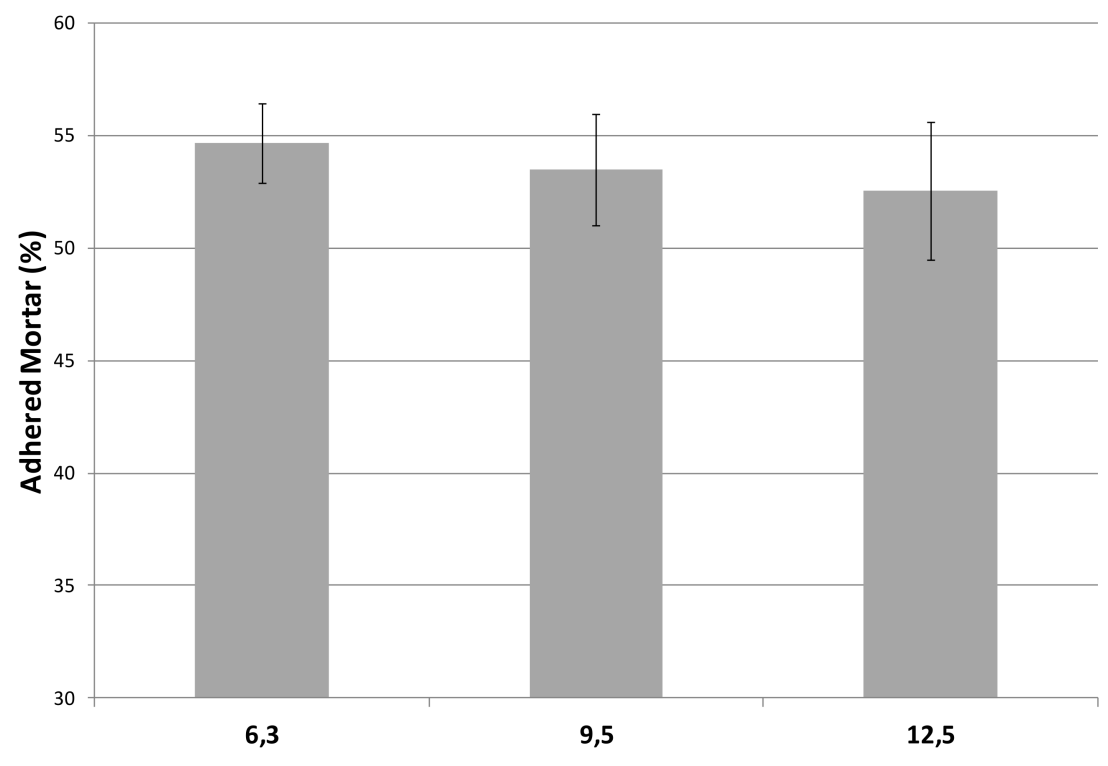

Figure 5. Amount of adhered mortar for each size of recycled aggregates (RA).

Figure 6 shows the SEM analysis of RA. Not only the RA and the old adhered mortar can be observed, but also the microscopic fissures that the debris grinding provokes in the aggregates and that can affect the mechanical properties of the material. EDS analysis of RA (Figure 7) shows that the main components of the RA are silica, calcium, and aluminium. 


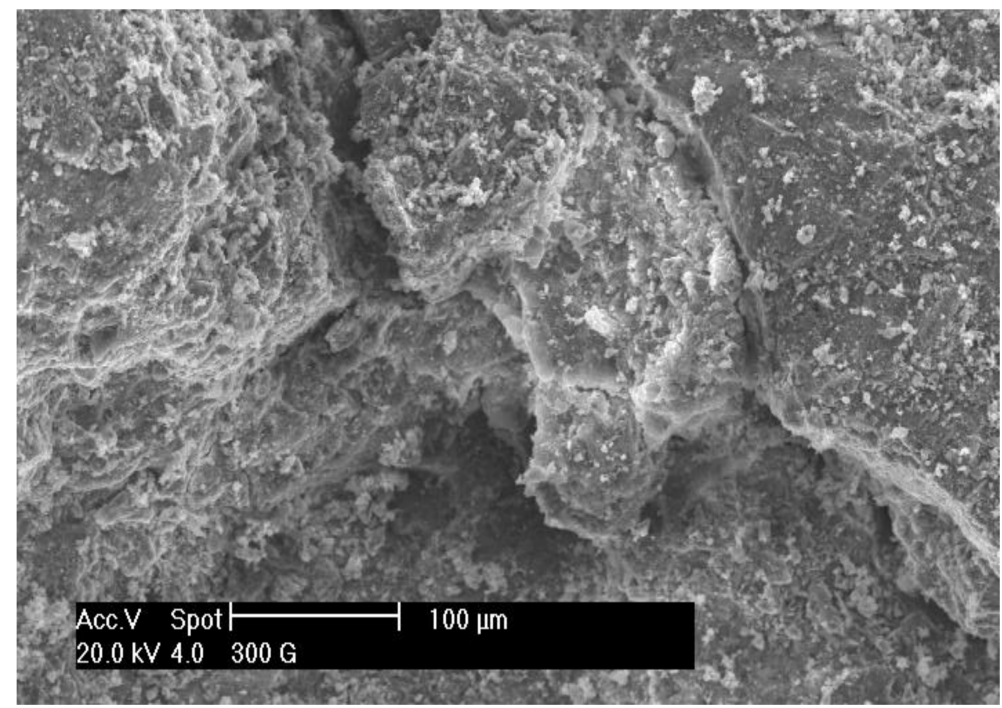

Figure 6. SEM micrograph of RA.

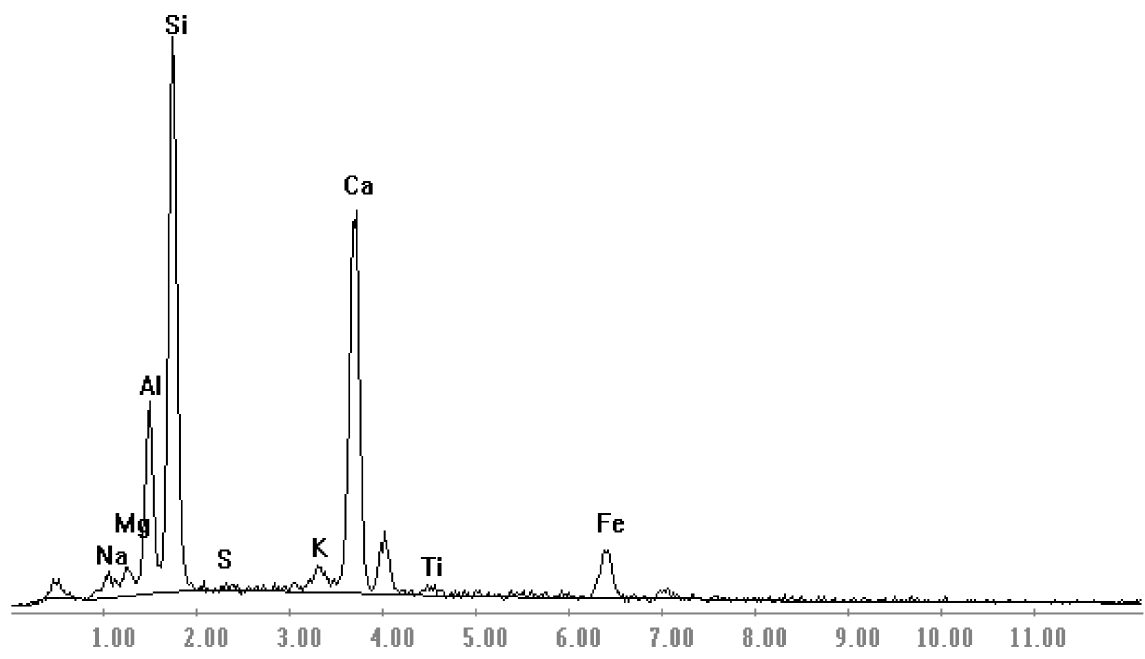

Figure 7. EDS analysis of RA.

Table 2 shows the physical properties of the coarse aggregates that were obtained following the technical regulations ASTM C127-15 and ASTM C128-15. The presence of the old mortar adhered to the surfaces of the aggregates, and its porosity, is responsible for the lower density values of the RA (around 6\% lower than those of natural aggregates, NA) and the increase in the water absorption values (around 2.5 times higher than in NA).

Table 2. Physical properties of coarse aggregates.

\begin{tabular}{cccccc}
\hline \multirow{2}{*}{ Aggregates } & Size(mm) & $\begin{array}{c}\text { Bulk Specific Gravity (Saturated } \\
\text { Surface Dry, SSD) }\left(\mathbf{k g} / \mathbf{m}^{3}\right)\end{array}$ & $\begin{array}{c}\text { Bulk Specific } \\
\text { Gravity }\left(\mathbf{k g} / \mathbf{m}^{3}\right)\end{array}$ & $\begin{array}{c}\text { Apparent Specific } \\
\text { Gravity }\left(\mathbf{k g} / \mathbf{m}^{3}\right)\end{array}$ & Absorption(\%) \\
\hline \multirow{3}{*}{ NA } & $6.3-9.5$ & 2678 & 2629 & 2765 & 1.9 \\
\cline { 2 - 6 } & $9.5-12.5$ & 2687 & 2642 & 2767 & 1.7 \\
\cline { 2 - 6 } & $12.5-19.3$ & 2699 & 2661 & 2765 & 1.4 \\
\hline \multirow{3}{*}{ RA } & $6.3-9.5$ & 2510 & 2390 & 2720 & 5.0 \\
\cline { 2 - 6 } & $9.5-12.5$ & 2530 & 2430 & 2720 & 4.4 \\
\cline { 2 - 6 } & $12.5-19.3$ & 2530 & 2440 & 2700 & 4.0 \\
\hline
\end{tabular}




\subsection{Sample Preparation}

The aim of this study is to compare the mechanical properties (compressive strength, flexural strength, and Young's modulus) of concretes made using CBP, CBP and RA, and a control concrete (CC) without recycled materials. To assess these differences, a constant water-to-binder (cement + fine addition) ratio of 0.42 was considered for all samples.

Three different percentages of cement were replaced by CBP: $5 \%, 10 \%$, and $15 \%$,in samples only with NA (specimens named CBP5-RA0, CBP10-RA0, and CBP15-RA0, respectively) and in samples where $30 \%$ of NA were replaced by RA (specimens named CBP5-RA30, CBP10-RA30, and CBP15-RA30, respectively).

The concrete mixtures for the different series of manufactured specimens are shown in Table 3 together with the corresponding slump test results.

Table 3. Concrete mixtures for the different series of specimens.

\begin{tabular}{cccccccc}
\hline Series & $\begin{array}{c}\text { NA } \\
(\mathbf{2 . 3 6}-\mathbf{1 9 . 0} \mathbf{~ m m}) \\
\mathbf{( k g )}\end{array}$ & $\begin{array}{c}\text { RA } \\
\mathbf{( 6 . 3 - 1 9 . 0 ~} \mathbf{~ m m}) \\
\mathbf{( k g})\end{array}$ & Cement (kg) & CBP (kg) & Sand (kg) & Water (L) & Slump (cm) \\
\hline CC & 920 & - & 382.0 & - & 877 & 203 & 3.0 \\
CBP5-RA0 & 920 & - & 362.9 & 19.1 & 877 & 203 & 3.5 \\
CBP10-RA0 & 920 & - & 343.8 & 38.2 & 877 & 203 & 5.0 \\
CBP15-RA0 & 920 & - & 324.7 & 57.3 & 877 & 203 & 6.5 \\
CBP5-RA30 & 644 & 276 & 362.9 & 19.1 & 877 & 203 & 3.5 \\
CBP10-RA30 & 644 & 276 & 343.8 & 38.2 & 877 & 203 & 4.0 \\
CBP15-RA30 & 644 & 276 & 324.7 & 57.3 & 877 & 203 & 1.0 \\
\hline
\end{tabular}

The procedure followed to manufacture all the specimens was the same. They were manufactured under laboratory conditions and then demolded after $24 \mathrm{~h}$; during the curing time, they were immersed in water with lime under a constant temperature of $23 \pm 3^{\circ} \mathrm{C}$. After this procedure, they were put to the different tests.

To test the compressive strength, four different curing times were considered: 7, 14, 28, and 90 days. A hydraulic press with a maximum capacity of $3000 \mathrm{kN}$ was used on cylindrical $150 \Phi \times$ $300 \mathrm{~mm}$ samples to calculate the compressive strength, following the standard ASTM C39/C39.

The curing times considered for the flexural strength tests were 28 and 90 days, and following ASTM C78 standards, it was tested on prism $150 \times 150 \times 530 \mathrm{~mm}$ specimens.

As the ASTM C469 dictates, the static elastic modulus was tested on cylindrical $150 \Phi \times 300 \mathrm{~mm}$ samples, after 28 curing days.

The dry density of the samples after 28 curing days was also studied to consider its effects in the final mechanical properties of the different mixtures.

\section{Results and Discussion}

\subsection{Density}

The dry density of all samples after 28 curing days is shown in Figure 8. Series CBP5-RA0 and CBP10-RA0 show slightly higher dry densities $\left(2550 \mathrm{~kg} / \mathrm{m}^{3}\right.$ and $2569 \mathrm{~kg} / \mathrm{m}^{3}$, respectively) than the one of the CC $\left(2525 \mathrm{~kg} / \mathrm{m}^{3}\right)$. Small amounts of CBP fill the pores, releasing the water, because it has higher specific surface values than cement, increasing the density and compactness of the concrete [45,46]. According to Silva et al. [46], the filler effect of the CBP particles reaches a limit, agreeing with the smaller value obtained when the percentage of CBP increases to $15 \%$ in series CBP15-RA0 $\left(2520 \mathrm{~kg} / \mathrm{m}^{3}\right)$. Once having exceeded that limit, the excess particles start to occupy the space of the material to which they are replacing (cement, in this case) which explains the slightly lower density of series CBP15-RA0, with a value of $2520 \mathrm{~kg} / \mathrm{m}^{3}$, because CBP has a slightly lower density compared to cement. 


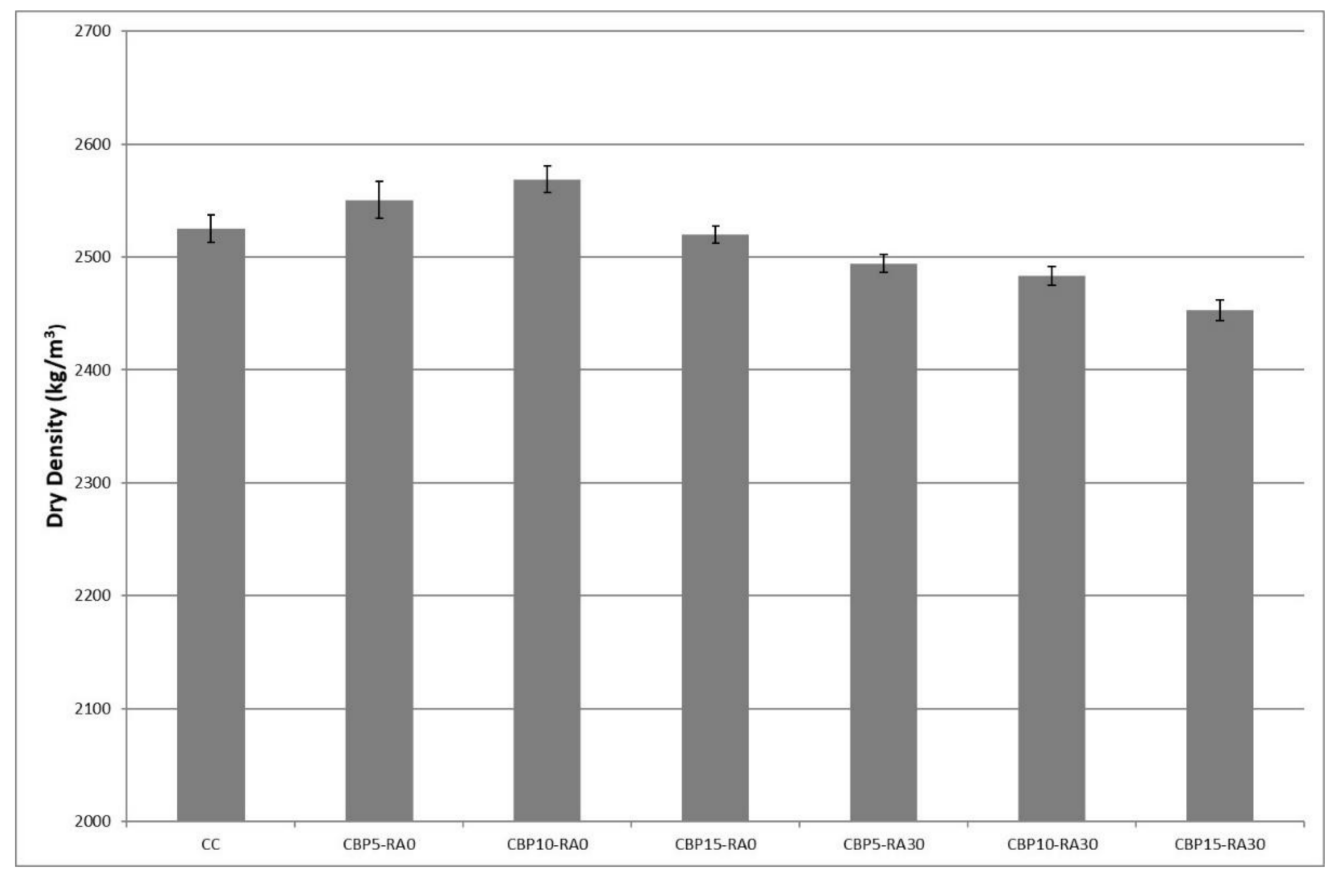

Figure 8. Dry bulk density of hardened concrete after 28 curing days.

Series with RA present lower densities in all cases with values that decrease when the percentage of CBP increases, ranging from $2494 \mathrm{~kg} / \mathrm{m}^{3}$ (series CBP5-RA30) to $2452 \mathrm{~kg} / \mathrm{m}^{3}$ (series CBP15-RA30), due to the lower density values of RA with respect to NA.

\subsection{Compressive Strength}

Results are shown in Table 4, in which "Std\%" is the standard deviation in percentage.

Table 4. Results of compressive strength, flexural strength, and elastic modulus.

\begin{tabular}{|c|c|c|c|c|c|c|c|c|}
\hline & & $\mathrm{CC}$ & CBP5-RA0 & CBP10-RA0 & CBP15-RA0 & CBP5-RA30 & CBP10-RA30 & CBP15-RA30 \\
\hline \multirow{5}{*}{$\begin{array}{l}\text { Compressive } \\
\text { Strength (MPa) }\end{array}$} & 7 days & 19.05 & 21.14 & 20.63 & 20.45 & 17.46 & 15.35 & 14.49 \\
\hline & Std\% & 2.5 & 0.3 & 1.3 & 0.9 & 1.2 & 3.0 & 3.9 \\
\hline & $\mathrm{Std} \%$ & 4.0 & 2.2 & 3.3 & 6.9 & 3.8 & 1.7 & 3.8 \\
\hline & 28 days & 32.34 & 32.93 & 31.77 & 32.21 & 33.51 & 30.18 & 28.93 \\
\hline & Std\% & 1.7 & 5.3 & 2.3 & 2.4 & 6.8 & 4.3 & 3.3 \\
\hline \multirow{4}{*}{$\begin{array}{l}\text { Flexural Strength } \\
\qquad(\mathrm{MPa})\end{array}$} & 28 days & 3.40 & 3.29 & 3.33 & 3.42 & 3.13 & 3.64 & 2.84 \\
\hline & Std $\%$ & 1.1 & 4.9 & 7.6 & 4.0 & 0.7 & 1.1 & 2.3 \\
\hline & 90 days & 5.16 & 4.68 & 4.57 & 4.85 & 4.49 & 4.74 & 4.39 \\
\hline & Std\% & 2.7 & 3.2 & 4.4 & 4.7 & 2.3 & 2.8 & 1.4 \\
\hline
\end{tabular}

Figures 9 and 10 show the compressive strength results.

When CBP is used in the absence of RA (series CBP5-RA0, CBP10-RA0, and CBP15-RA0) there are no significant variations with respect to the values obtained for the CC. These results agree with the ones obtained by Kulovaná et al. [22], who concluded that the use of up to $20 \%$ of CBP does not affect the compressive strength of concretes. The chemical composition of CBP and the grain size distribution of its particles, with a maximum size of $35 \mu \mathrm{m}$ (Figure 4), made CBP present higher Blaine 
values than the reference cement, provoking a filler effect that, added to the pozzolanic characteristics, reduces the capillarity, resulting in denser matrixes with similar strengths to the CC [46]. According to Naceri and Hamina [47], the artificial pozzolan (brick waste) added to cement can enhance the mechanical resistance of the mortar in the long term (90 curing days). Following their studies, mortars that contain up to $10 \%$ of brick waste can reach a strength comparable to the one given by a reference mortar, due to the variation in the $\mathrm{SiO}_{2}$ and $\mathrm{Al}_{2} \mathrm{O}_{3}$ content and the $\mathrm{CaO} / \mathrm{SiO}_{2}$ ratio.

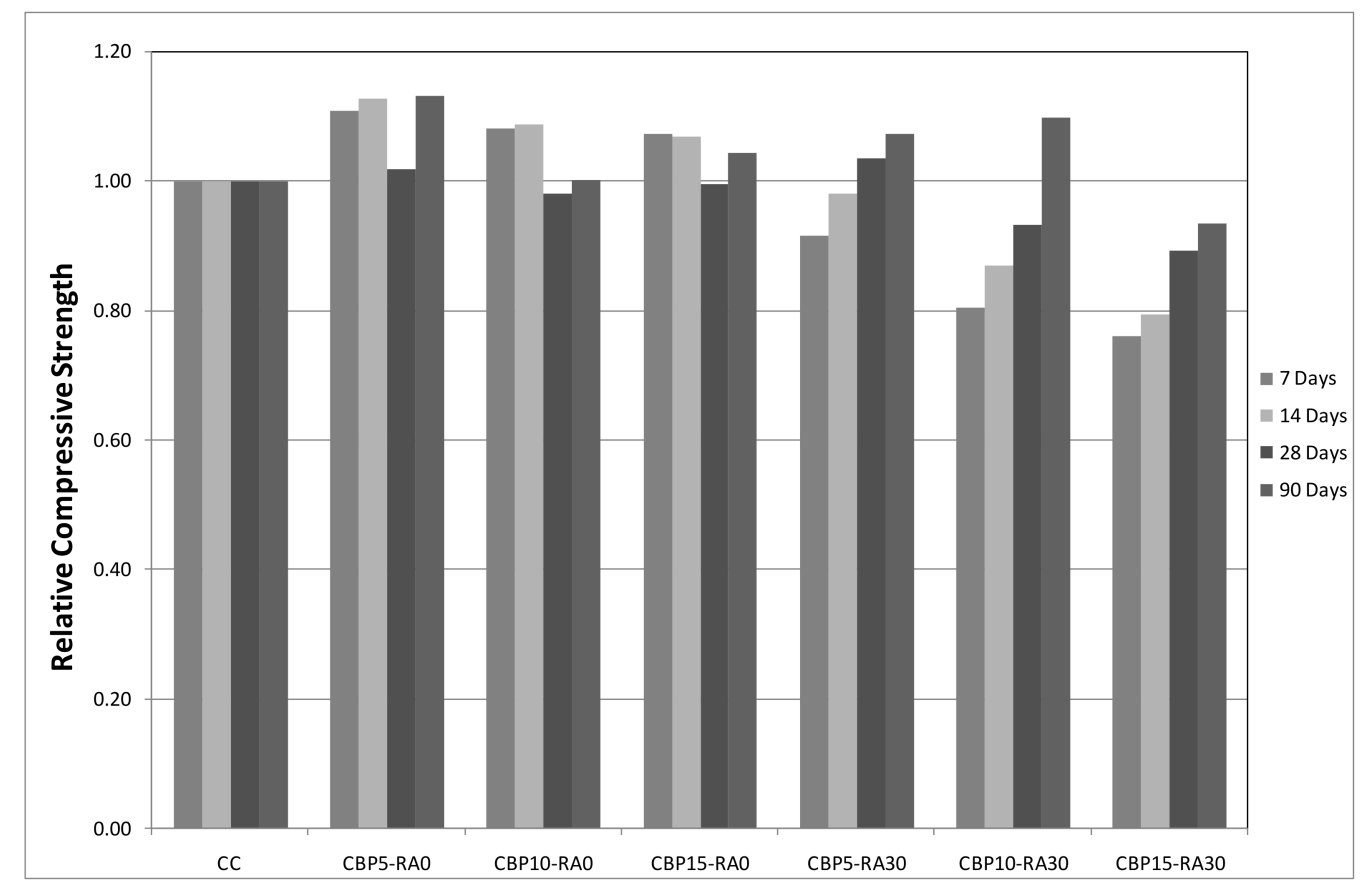

Figure 9. Variation of compressive strength compared to control specimens (CC).

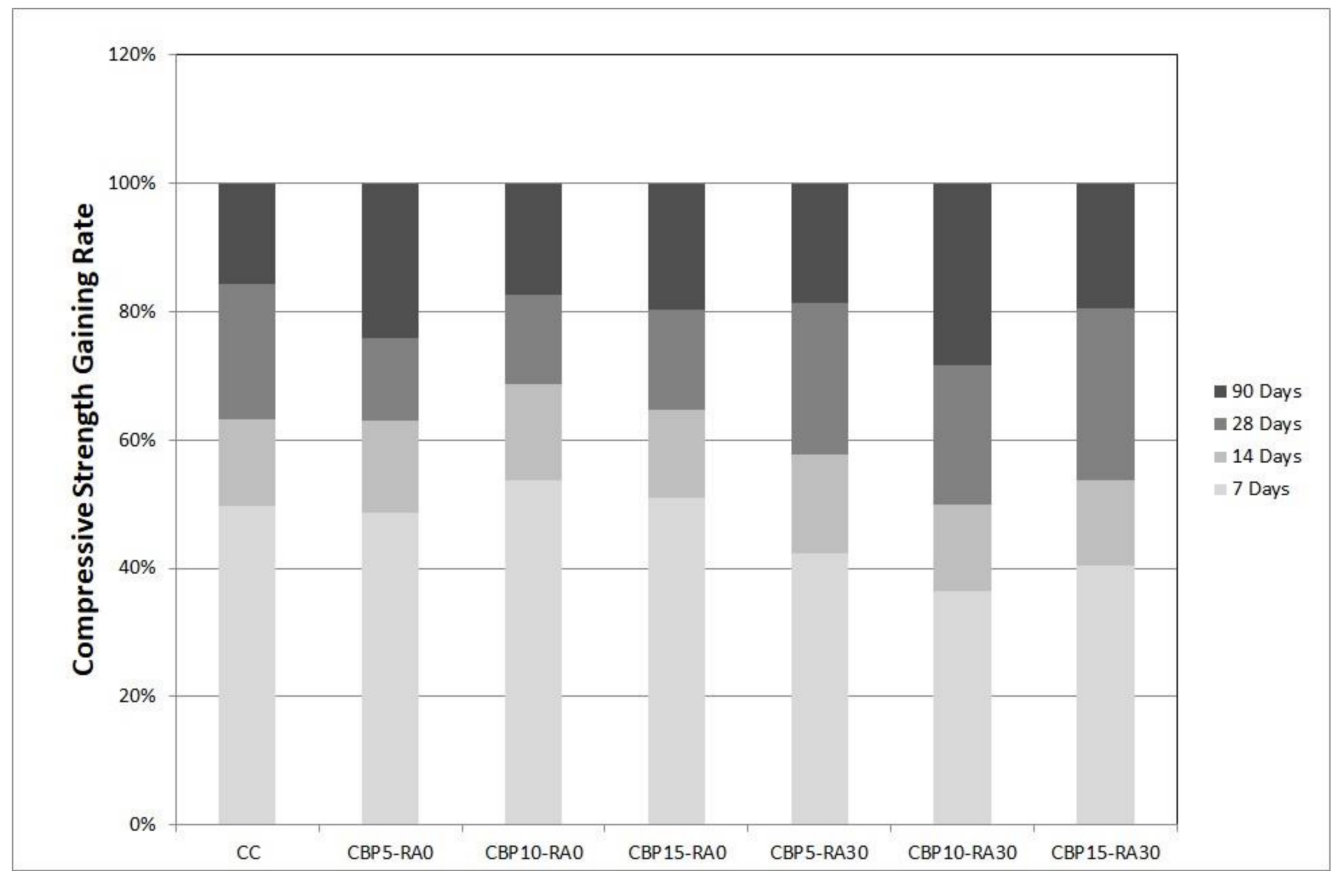

Figure 10. Compressive strength gaining rates with the curing time. 
When both residues are used simultaneously (series CBP5-RA30, CBP10-RA30, and CBP15-RA30), the compressive strength decreases when the amount of CBP increases, particularly for the smaller curing times (up to 20-25\% after seven curing days). The behavior changes for longer curing times. After 28 curing days, the sample CBP5-RA30 exhibits a 4\% increase in the compressive strength with respect to the $\mathrm{CC}$ value. Increasing the $\mathrm{CBP}$ replacement provokes a gradual decrease in the compressive strength, reaching a loss of $11 \%$ when $15 \%$ of the cement is replaced with CBP (series CBP15-RA30). After 90 curing days, these differences attenuate and the series with maximum replacements (CBP15-RA30) presents a decrease of only $6 \%$ from the CC value. This gradual enhancement of the compressive strength with the curing time when both residuals are used can be clearly observed in Figures 9 and 10.

All the series containing RA present a late gaining rate, obtaining almost $50 \%$ of the final compressive strength value (90 curing days) during the last curing periods (Figure 10). The additional production of calcium-silicate-hydrate (C-S-H) gel at late stages and the internal curing process may favor this behavior. According to O'Farrell et al. [48], the silicates of the CBP react with the calcium hydroxide $(\mathrm{CH})$, producing additional C-S-H gel and provoking a refinement in the pore structure, leading to an increase of the strength at late ages. This behavior has also been observed in concrete mixtures that use residuals with silica content together with RA [49]. On their behalf, Ge et al. [26] noticed that a significant amount of water is absorbed by the CBP during the prewetting time. As the relative humidity decreases with the cement hydration, the CBP would release the absorbed water, contributing to the cement hydration and improving the strength at later ages. The high absorption values of RA amplify this effect in the samples that contain both residuals. The filler effect $[20,26,50]$ and these late gaining rates in compressive strength allow series CBP5-RA30 (after 28 and 90 curing days) and CBP10-RA30 (after 90 curing days) to reach slightly higher compressive strength values than CC.

These results reveal the benefits of the use of CBP in concretes with RA, because the properties of the CBP can compensate the weaknesses that RA can cause [31,32]. However, the filler effect of the CBP and the internal curing of RA must stop at a certain percentage of CBP replacement, existing at an optimal content of the residual, further from which the benefits of the enhanced microstructure would be lost [28]. The optimal content may vary depending of the nature of the aggregates that are used.

\subsection{Flexural Strength}

Results for flexural strength after 28 and 90 curing days are shown in Figure 11.

When CBP is used alone with no RA, the flexural strength after 28 curing days does not present significant variations from the values of CC.

These results contrast with the conclusions obtained in previous investigations, where flexural strength decreases when increasing the amount of CBP. However, these investigations consider CBP replacements of over $20 \%$, and small amounts of CBP may not affect significantly the flexural strength of the concrete. After 90 curing days, the differences increase, with losses between $6 \%$ and $11 \%$.

When both residuals are used together, flexural strength presents more significant changes with respect to CC, showing losses over $16 \%$ for the highest CBP replacement after 28 curing days. After 28 curing days, series CBP5-RA30 and CBP15-RA30 present losses of $8 \%$ and $16 \%$ that can be attributed to the use of RA. These results agree with other analyses of RA [51,52], concluding that even though compressive strength can equal the CC value, a loss in flexural strength of around $10 \%$ seems to be unavoidable. Increasing the curing days has the same effect with or without RA on flexural strength, since the losses generally increase after 90 curing days.

The reduction of the relative strengths of the analysed series at 90 days, compared to those observed at 28 days, could be due to a lower development of the bond between the aggregates and the cement paste when CBP is used. Nevertheless, this argument must be studied in depth in future research. 


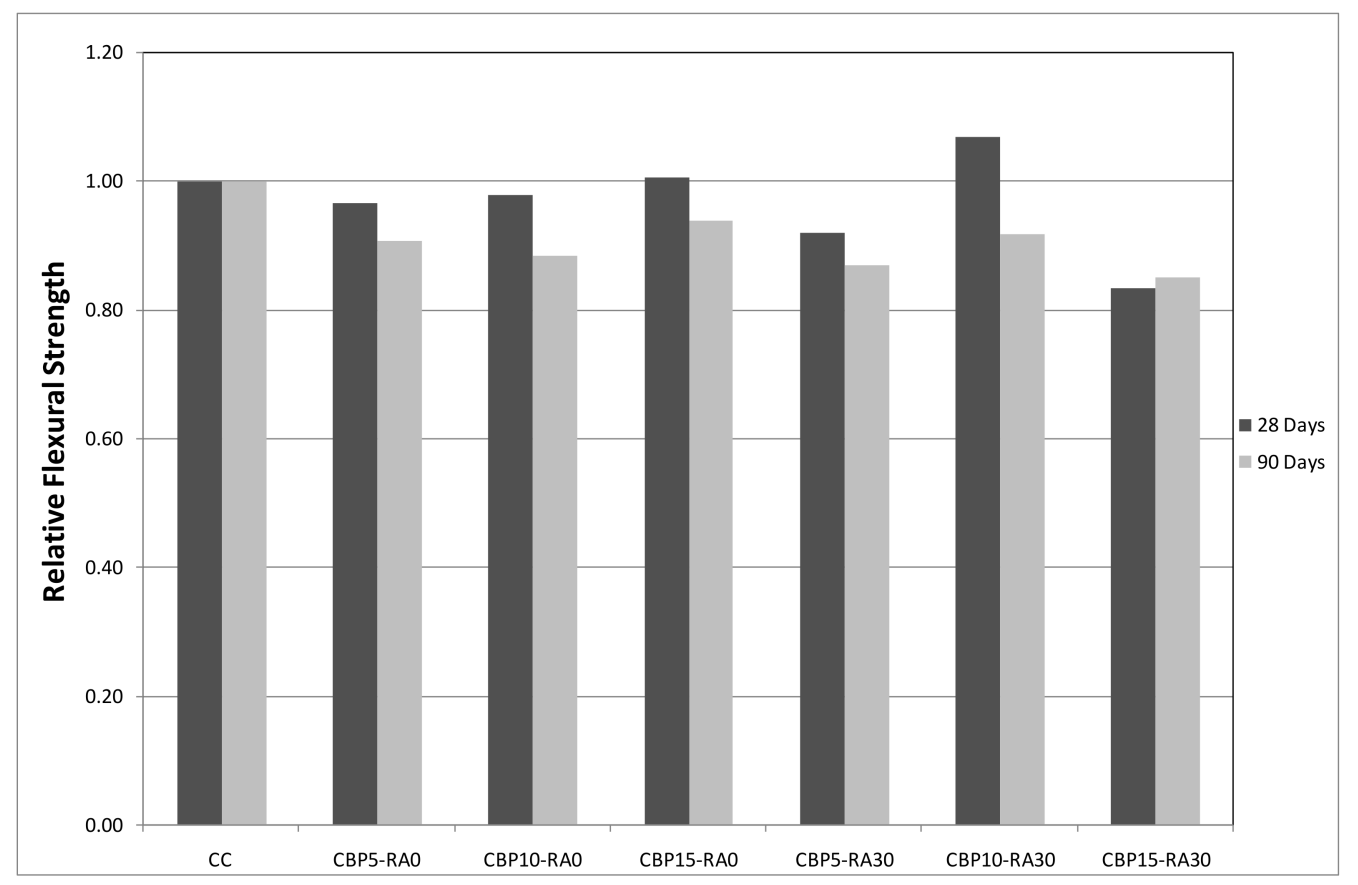

Figure 11. Variation of flexural strength compared to control specimens (CC).

\subsection{Static Elastic Modulus}

The static elastic modulus presents losses that vary between $1 \%$ and $12 \%$ of the $\mathrm{CC}$ value (Figure 12).

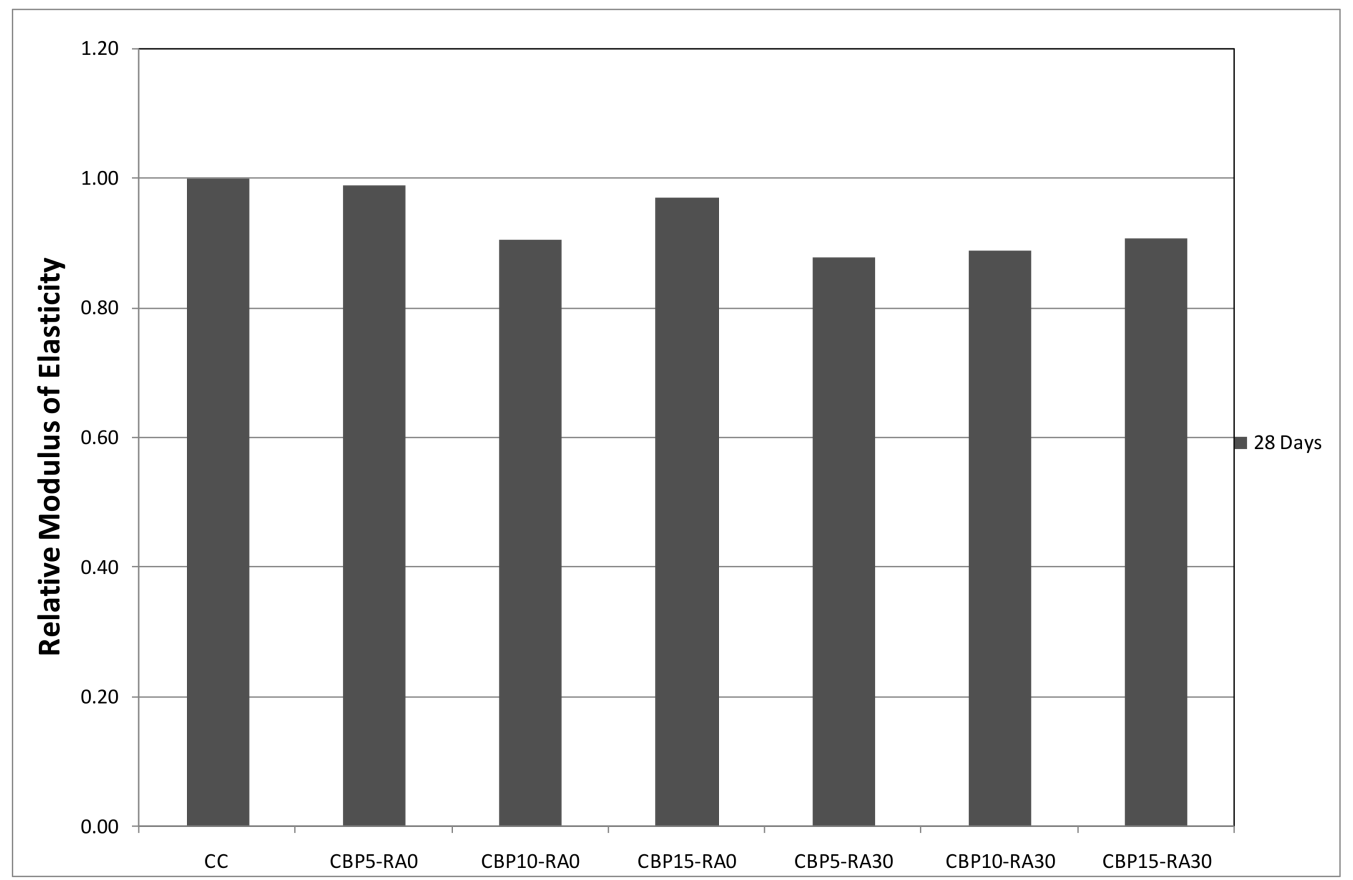

Figure 12. Variation of the static elastic modulus compared to control specimens (CC).

Ge et al. $[25,26]$ conclude that replacing cement by CBP reduces the elastic modulus, due to the low modulus of the brick. The losses are slightly higher when the use of CBP is combined with RA, varying between $9 \%$ and $12 \%$ with respect to the CC. The elasticity modulus is influenced by the 
modulus of the coarse aggregates [35], meaning that this increase in the losses can be controlled by controlling the quality of the original concrete from which RA derive. In this study, RA were obtained from medium-to-low-quality concretes, thus affecting the elastic modulus.

\subsection{Comparison with Normative}

To compare the experimental behavior of concretes with recycled materials with the ones estimated by technical regulations, ACI 318 and Eurocode 2 (EC2) are used to calculate the flexural strength and the elastic modulus using the compressive strength values.

ACI 318 proposes the following equations:

$$
\begin{aligned}
& f_{r}=0.62 \sqrt{f^{\prime}}{ }_{c} \\
& E_{c}=4700 \sqrt{f^{\prime}{ }_{c}}
\end{aligned}
$$

EC2 proposes the following equations:

$$
\begin{gathered}
f_{c t m, f l}=\max \left(\left(1.6-\frac{h}{1000}\right) f_{c t m}, f_{c t m}\right) \\
E_{c}=22\left(\frac{f_{c m}}{10}\right)^{0.30}
\end{gathered}
$$

where $f_{r}$ is flexural strength; $E_{c}$ the static elastic modulus; $f^{\prime}{ }_{c}$ the compressive strength after 28-days curing; $f_{c t m, f l}$ the flexural strength following EC2; $h$ the height of the specimen; and $f_{c t m}$ the mean of the flexural strength obtained using $f_{c t m}=0.3\left(f_{c k}\right)^{2 / 3}$, where $\mathrm{f}_{c k}$ are the experimental values obtained for the compressive strength minus $8 \mathrm{MPa}$.

In Figure 13, the results of Equations (1) and (3) are showed together with the experimental results for flexural strength.

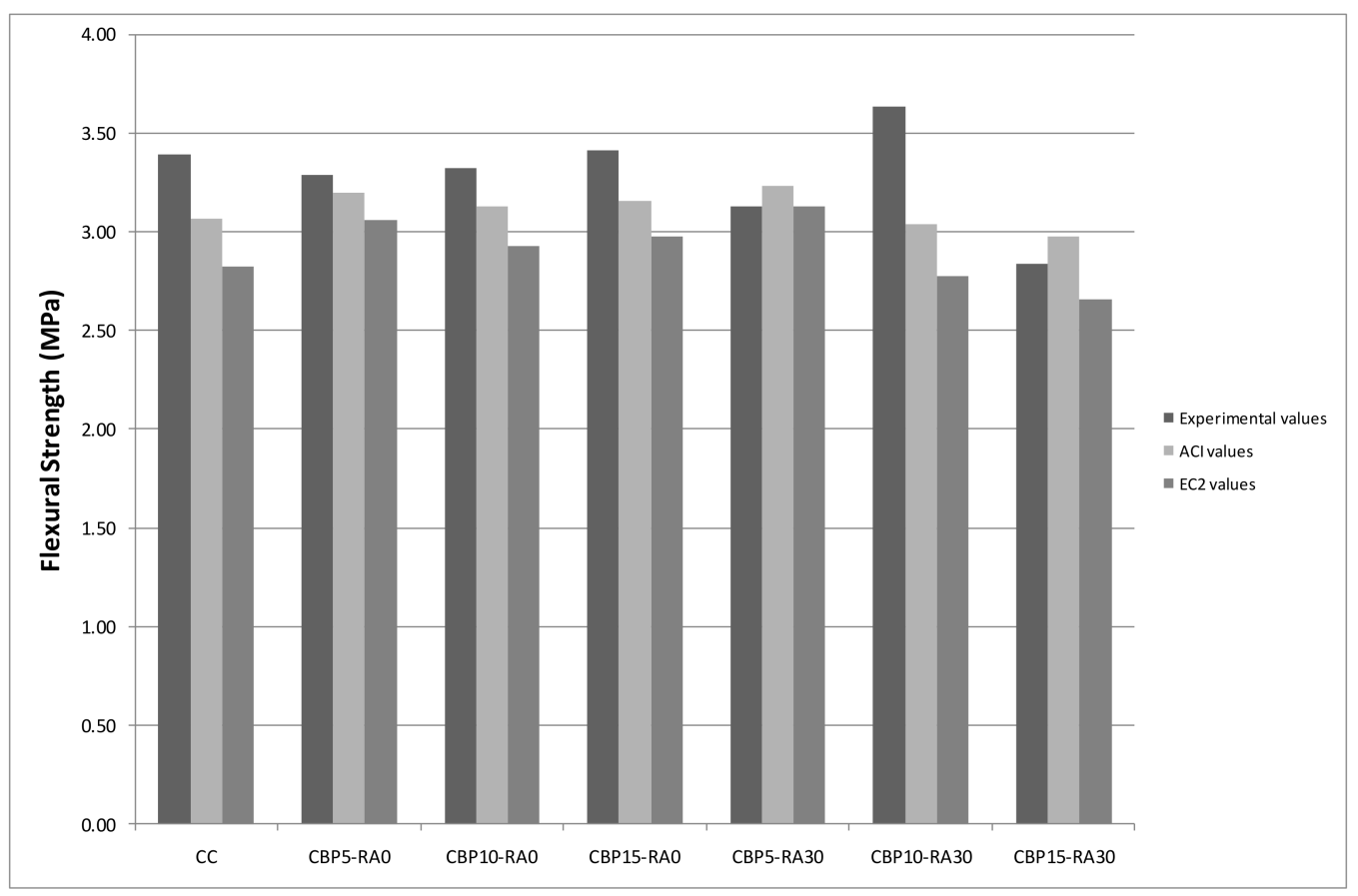

Figure 13. Flexural strength after 28 curing days. Experimental and theoretical ACI 318 and EC2 values. 
Except for the series CBP5-RA30 and CBP15-RA30, all the specimens present higher values than the theoretical ones (increasing up to $31 \%$ of their values), and even these series present an equal or higher value that the one obtained following the EC2.

When Equation (1) (proposed by ACI) is used, the experimental values obtained for CC exceed the theoretical ones by $11 \%$. If $\mathrm{CBP}$ is added to the mixture, this increase drops to the range of $3-8 \%$, and if both residuals are used together, the results show values that vary between a decrease of $5 \%$ and an increase of $19 \%$. This last significant increase corresponds to the sample CBP10-RA30, and breaks the general trend of the effects of the use of both residuals together. This high experimental value obtained for the flexural strength may be due to the refining of the pore structure and the internal curing of the RA due to the presence of a certain amount of CBP.

When Equation (3) (proposed by EC2) is used, the experimental values for CC exceed the theoretical ones by $20 \%$. If CBP is added without RA, this increase drops to the range of $7-15 \%$. When RA are added, the increase of the experimental values ranges between $0 \%$ and $31 \%$. Again, the sample CBP10-RA30 is the one breaking the general trend, with an increase of $31 \%$.

Considering these results, the theoretical values obtained using the proposed equations are conservative enough when CBP is used alone. However, when RA are included in the tests, the equations are not enough and the samples are experimentally weaker than expected. The difference is significant when ACI equations are applied, suggesting that technical regulations should consider proposing new equations for the flexural strength when RA are used to manufacture recycled concretes.

Figure 14 shows the results for the static elastic modulus.

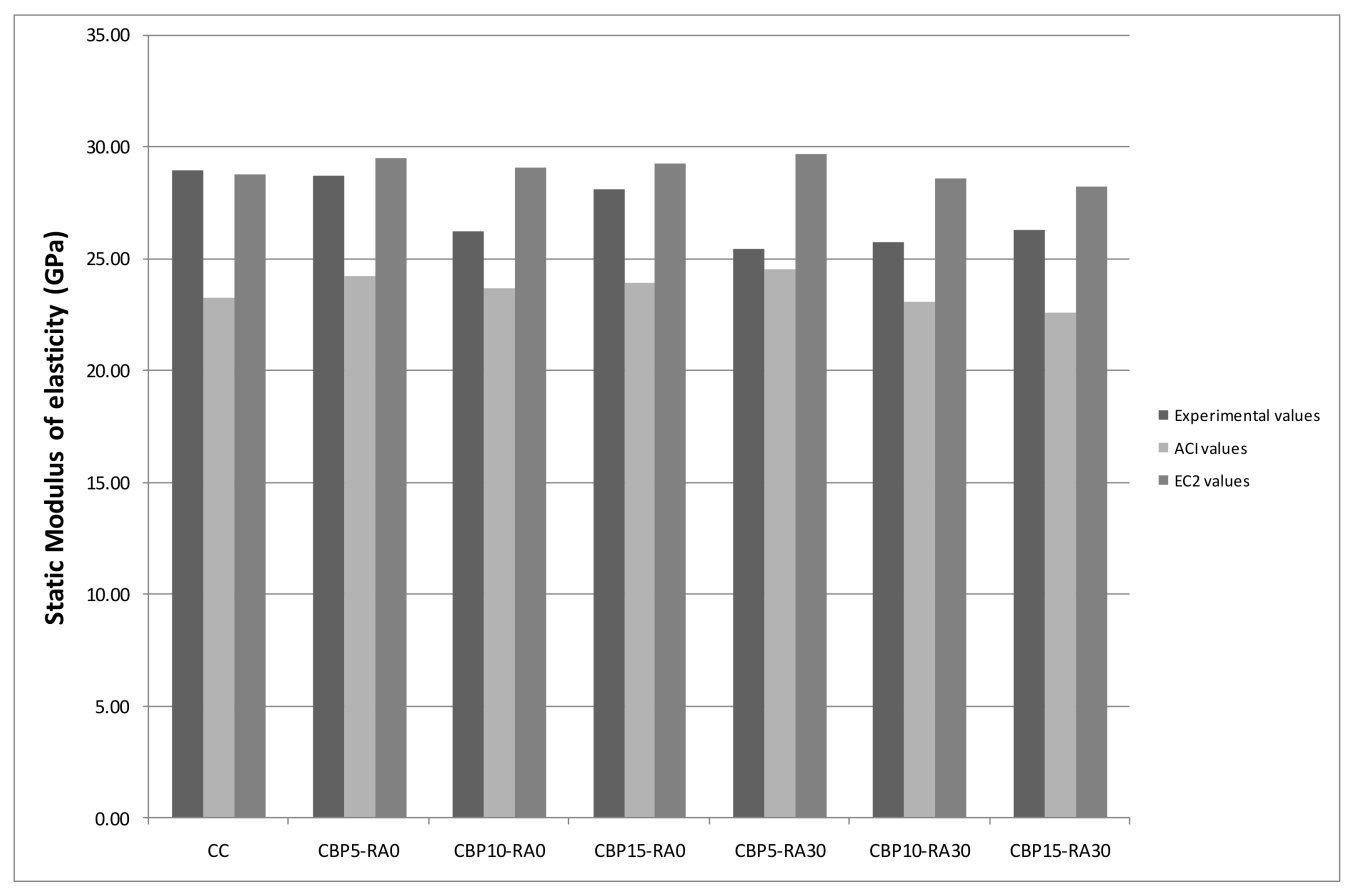

Figure 14. Static elastic modulus. Experimental and theoretical ACI 318 and EC2 values.

The experimental values obtained for CC are $25 \%$ higher than the theoretical ACI (Equation(2)) ones. When CBP is used alone, this increase is reduced to the range of $11 \%-18 \%$; and again, when RA are added to the mixture, to $4-16 \%$.

The results obtained with Equation (4) (applying EC2) reveal that only when applied to the CC is this regulation conservative enough, showing an increase of only $1 \%$ of the experimental value with respect to the theoretical one. When residuals are used, theoretical values are over the experimental ones in the range of $3-10 \%$ if only CBP is used, and $7-14 \%$ if both are used. These results suggest that when residuals are used, EC2 equations are not as conservative as desirable, and new proposals should be evaluated to calculate the static elastic modulus of recycled concretes. 


\section{Conclusions}

The main conclusions that can be drawn from the results previously discussed can be summarized as follows:

- Replacing up to $15 \%$ of cement with CBP does not alter significantly the compressive strength of concretes with natural coarse aggregates or with up to $30 \%$ RA replacement if enough curing days are considered.

- The use of a small percentage of CBP together with RA strengthens the concrete matrix, compensating for the strength losses due to the use of RA.

- After 28 curing days, the flexural strength does not present losses when up to $15 \%$ of cement is replaced by CBP, if no RA are used. At 90 days, the series show differences between $6 \%$ and $11 \%$ compared to control concrete.

- Flexural strength is mainly affected by the use of RA, observing losses of up to $16 \%$ after 28 curing days when it is combined with the reuse of CBP. At 90 days, these losses are kept between $8 \%$ and $15 \%$.

- The use of CBP as a cement replacement without RA affected the elastic modulus with losses between $1 \%$ and $9 \%$, due to the low elastic modulus of the bricks.

- The use of CBP together with RA increases the loss in the elastic modulus between $9 \%$ and $12 \%$.

- Equations proposed by the different technical regulations tested in this analysis to calculate the flexural strength and the static elastic modulus are not always able to predict conservatively enough the behavior of recycled concretes. Performing further studies is suggested to re-evaluate these regulations when reused materials are included in concrete manufacturing.

- Further studies are suggested to evaluate if a certain proportion of RA and CBP can optimize the performance of the recycled concrete. The results suggest that the internal curing of the RA due to the presence of a certain amount of CBP may lead to an optimal combination of both.

Acknowledgments: This analysis is part of the Project FONDECYT 1180414 "Improving thermal insulation of fired clay bricks by mixing clay and wastes. A contribution to building energy performance, waste management and air pollution mitigation", funded by CONICYT, Chile.

Author Contributions: Viviana Letelier wrote the paper. Viviana Letelier, Pedro Muñoz, Ester Tarela, and José Marcos Ortega performed the experiments. José Marcos Ortega and Giacomo Moriconi supervised the research work and revised the paper. All the authors contributed to conceive and design the experiments, and to analyse and discuss the results.

Conflicts of Interest: The authors declare no conflict of interest.

\section{References}

1. Lin, K.-L.; Chang, J.-C. Feasibility of recycling waste diatomite and fly ash cosintered as porous ceramics. Environ. Prog. Sustain. Energy 2013, 32, 25-34. [CrossRef]

2. Pasetto, M.; Baldo, N. Recycling of waste aggregate in cement bound mixtures for road pavement bases and sub-bases. Constr. Build. Mater. 2016, 108, 112-118. [CrossRef]

3. Pasetto, M.; Baldo, N. Experimental analysis of hydraulically bound mixtures made with waste foundry sand and steel slag. Mater. Struct. 2015, 48, 2489-2503. [CrossRef]

4. United Nations Environment Programme. Common carbon metric for measuring energy use and reporting greenhouse gas emissions from building operations 2009. Available online: http://wedocs.unep.org/ handle/20.500.11822/7922 (accessed on 8 March 2018).

5. Liu, Q.; Tong, T.; Liu, S.; Yang, D.; Yu, Q. Investigation of using hybrid recycled powder from demolished concrete solids and clay bricks as a pozzolanic supplement for cement. Constr. Build. Mater. 2014, 73, 754-763. [CrossRef]

6. Xiao, J.; Li, W.; Fan, Y.; Huang, X. An overview of study on recycled aggregate concrete in China (1996-2011). Constr. Build. Mater. 2012, 31, 364-383. [CrossRef] 
7. Robayo-Salazar, R.A.; Rivera, J.F.; Mejía de Gutiérrez, R. Alkali-activated building materials made with recycled construction and demolition wastes. Constr. Build. Mater. 2017, 149, 130-138. [CrossRef]

8. Rakhimova, N.R.; Rakhimov, R.Z. Alkali-activated cements and mortars based on blast furnace slag and red clay brick waste. Mater. Des. 2015, 85, 324-331. [CrossRef]

9. Medina, C.; Banfill, P.F.G.; Sánchez De Rojas, M.I.; Frías, M. Rheological and calorimetric behaviour of cements blended with containing ceramic sanitary ware and construction/demolition waste. Constr. Build. Mater. 2013, 40, 822-831. [CrossRef]

10. Celik, K.; Meral, C.; Petek Gursel, A.; Mehta, P.K.; Horvath, A.; Monteiro, P.J.M. Mechanical properties, durability, and life-cycle assessment of self-consolidating concrete mixtures made with blended portland cements containing fly ash and limestone powder. Cem. Concr. Compos. 2015, 56, 59-72. [CrossRef]

11. Cordeiro, G.C.; Toledo Filho, R.D.; Tavares, L.M.; Fairbairn, E.M.R. Experimental characterization of binary and ternary blended-cement concretes containing ultrafine residual rice husk and sugar cane bagasse ashes. Constr. Build. Mater. 2012, 29, 641-646. [CrossRef]

12. Ortega, J.M.; Sánchez, I.; Climent, M.A. Influence of environmental conditions on durability of slag cement mortars. In Proceedings of the 2nd International Conference on Sustainable Construction Materials and Technologies, Ancona, Italy, 28-30 June 2010; pp. 277-287.

13. Pastor, J.L.; Ortega, J.M.; Flor, M.; López, M.P.; Sánchez, I.; Climent, M.A. Microstructure and durability of fly ash cement grouts for micropiles. Constr. Build. Mater. 2016, 117, 47-57. [CrossRef]

14. Ortega, J.M.; Esteban, M.D.; Rodríguez, R.R.; Pastor, J.L.; Sánchez, I. Microstructural Effects of Sulphate Attack in Sustainable Grouts for Micropiles. Materials 2016, 9, 905. [CrossRef] [PubMed]

15. Williams, M.; Ortega, J.M.; Sánchez, I.; Cabeza, M.; Climent, M.A. Non-Destructive Study of the Microstructural Effects of Sodium and Magnesium Sulphate Attack on Mortars Containing Silica Fume Using Impedance Spectroscopy. Appl. Sci. 2017, 7, 648. [CrossRef]

16. Böke, H.; Akkurt, S.; Ipekoğlu, B.; Uğurlu, E. Characteristics of brick used as aggregate in historic brick-lime mortars and plasters. Cem. Concr. Res. 2006, 36, 1115-1122. [CrossRef]

17. Puertas, F.; Barba, A.; Gazulla, M.F.; Gómez, M.P.; Palacios, M.; Martínez-ramírez, S. Ceramic wastes as raw materials in portland cement clinker fabrication: Characterization and alkaline activation. Mater. Constr. 2006, 56, 73-84. [CrossRef]

18. Vieira, T.; Alves, A.; de Brito, J.; Correia, J.R.; Silva, R.V. Durability-related performance of concrete containing fine recycled aggregates from crushed bricks and sanitary ware. Mater. Des. 2016, 90, 767-776. [CrossRef]

19. Aliabdo, A.A.; Abd-Elmoaty, A.-E.M.; Hassan, H.H. Utilization of crushed clay brick in concrete industry. Alexandria Eng. J. 2014, 53, 151-168. [CrossRef]

20. Letelier, V.; Tarela, E.; Muñoz, P.; Moriconi, G. Combined effects of recycled hydrated cement and recycled aggregates on the mechanical properties of concrete. Constr. Build. Mater. 2017, 132, 365-375. [CrossRef]

21. Serpell, R.; Lopez, M. Reactivated cementitious materials from hydrated cement paste wastes. Cem. Concr. Compos. 2013, 39, 104-114. [CrossRef]

22. Kulovaná, T.; Vejmelková, E.; Keppert, M.; Rovnaníková, P.; Keršner, Z.; Černý, R. Mechanical, durability and hygrothermal properties of concrete produced using Portland cement-ceramic powder blends. Struct. Concr. 2016, 17, 105-115. [CrossRef]

23. Katzer, J. Strength performance comparison of mortars made with waste fine aggregate and ceramic fume. Constr. Build. Mater. 2013, 47, 1-6. [CrossRef]

24. Lavat, A.E.; Trezza, M.A.; Poggi, M. Characterization of ceramic roof tile wastes as pozzolanic admixture. Waste Manag. 2009, 29, 1666-1674. [CrossRef] [PubMed]

25. Ge, Z.; Gao, Z.; Sun, R.; Zheng, L. Mix design of concrete with recycled clay-brick-powder using the orthogonal design method. Constr. Build. Mater. 2012, 31, 289-293. [CrossRef]

26. Ge, Z.; Wang, Y.; Sun, R.; Wu, X.; Guan, Y. Influence of ground waste clay brick on properties of fresh and hardened concrete. Constr. Build. Mater. 2015, 98, 128-136. [CrossRef]

27. Gonçalves, J.P.; Tavares, L.M.; Toledo Filho, R.D.; Fairbairn, E.M.R. Performance evaluation of cement mortars modified with metakaolin or ground brick. Constr. Build. Mater. 2009, 23, 1971-1979. [CrossRef]

28. Schackow, A.; Stringari, D.; Senff, L.; Correia, S.L.; Segadães, A.M. Influence of fired clay brick waste additions on the durability of mortars. Cem. Concr. Compos. 2015, 62, 82-89. [CrossRef]

29. Tam, V.W.Y.; Gao, X.F.; Tam, C.M.; Ng, K.M. Physio-chemical reactions in recycle aggregate concrete. J. Hazard. Mater. 2009, 163, 823-828. [CrossRef] [PubMed] 
30. Ismail, S.; Ramli, M. Engineering properties of treated recycled concrete aggregate (RCA) for structural applications. Constr. Build. Mater. 2013, 44, 464-476. [CrossRef]

31. Lee, G.C.; Choi, H.B. Study on interfacial transition zone properties of recycled aggregate by micro-hardness test. Constr. Build. Mater. 2013, 40, 455-460. [CrossRef]

32. Ismail, S.; Ramli, M. Mechanical strength and drying shrinkage properties of concrete containing treated coarse recycled concrete aggregates. Constr. Build. Mater. 2014, 68, 726-739. [CrossRef]

33. Tam, V.W.Y.; Gao, X.F.; Tam, C.M. Microstructural analysis of recycled aggregate concrete produced from two-stage mixing approach. Cem. Concr. Res. 2005, 35, 1195-1203. [CrossRef]

34. Seo, D.S.; Choi, H.B. Effects of the old cement mortar attached to the recycled aggregate surface on the bond characteristics between aggregate and cement mortar. Constr. Build. Mater. 2014, 59, 72-77. [CrossRef]

35. González, A.; Etxeberria, M. Experimental analysis of properties of high performance recycled aggregate concrete. Constr. Build. Mater. 2014, 52, 227-235. [CrossRef]

36. Pedro, D.; De Brito, J.; Evangelista, L. Influence of the use of recycled concrete aggregates from different sources on structural concrete. Constr. Build. Mater. 2014, 71, 141-151. [CrossRef]

37. Tam, V.W.Y.; Wang, K.; Tam, C.M. Assessing relationships among properties of demolished concrete, recycled aggregate and recycled aggregate concrete using regression analysis. J. Hazard. Mater. 2008, 152, 703-714. [CrossRef] [PubMed]

38. Padmini, A.K.; Ramamurthy, K.; Mathews, M.S. Influence of parent concrete on the properties of recycled aggregate concrete. Constr. Build. Mater. 2009, 23, 829-836. [CrossRef]

39. Li, X. Recycling and reuse of waste concrete in China. Part II. Structural behaviour of recycled aggregate concrete and engineering applications. Resour. Conserv. Recycl. 2009, 53, 107-112. [CrossRef]

40. Kwan, W.H.; Ramli, M.; Kam, K.J.; Sulieman, M.Z. Influence of the amount of recycled coarse aggregate in concrete design and durability properties. Constr. Build. Mater. 2012, 26, 565-573. [CrossRef]

41. Letelier, V.; Tarela, E.; Moriconi, G. Mechanical Properties of Concretes with Recycled Aggregates and Waste Brick Powder as Cement Replacement. Procedia Eng 2017, 171, 627-632. [CrossRef]

42. Pereira-De-Oliveira, L.A.; Castro-Gomes, J.P.; Santos, P.M.S. The potential pozzolanic activity of glass and red-clay ceramic waste as cement mortars components. Constr. Build. Mater. 2012, 31, 197-203. [CrossRef]

43. Pepe, M.; Toledo Filho, R.D.; Koenders, E.A.B.; Martinelli, E. Alternative processing procedures for recycled aggregates in structural concrete. Constr. Build. Mater. 2014, 69, 124-132. [CrossRef]

44. de Juan, M.S.; Gutiérrez, P.A. Study on the influence of attached mortar content on the properties of recycled concrete aggregate. Constr. Build. Mater. 2009, 23, 872-877. [CrossRef]

45. Harbi, R.; Derabla, R.; Nafa, Z. Improvement of the properties of a mortar with $5 \%$ of kaolin fillers in sand combined with metakaolin, brick waste and glass powder in cement. Constr. Build. Mater. 2017, 152, 632-641. [CrossRef]

46. Silva, J.; Brito, J.D.; Veiga, R. Incorporation of fine ceramics in mortars. Constr. Build. Mater. 2009, 23, 556-564. [CrossRef]

47. Naceri, A.; Hamina, M.C. Use of waste brick as a partial replacement of cement in mortar. Waste Manag. 2009, 29, 2378-2384. [CrossRef] [PubMed]

48. O'Farrell, M.; Wild, S.; Sabir, B.B. Pore size distribution and compressive strength of waste clay brick mortar. Cem. Concr. Compos. 2001, 23, 81-91. [CrossRef]

49. Nassar, R.-U.-D.; Soroushian, P. Strength and durability of recycled aggregate concrete containing milled glass as partial replacement for cement. Constr. Build. Mater. 2012, 29, 368-377. [CrossRef]

50. Letelier, V.; Tarela, E.; Muñoz, P.; Moriconi, G. Assessment of the mechanical properties of a concrete made by reusing both: Brewery spent diatomite and recycled aggregates. Constr. Build. Mater. 2016, 114, 492-498. [CrossRef]

51. RILEM TC 37-DRC. Demolition and Reuse of Concrete; E \& FN Spon: London, UK, 1992.

52. Ikeda, T.; Yamane, S.; Sakamoto, A. Strengths of concrete containing recycled concrete aggregate. In Demolition and Reuse of Concrete and Masonry; Kasai, Y., Ed.; Chapman and Hall: Tokyo, Japan, 1988; pp. 585-594.

(C) 2018 by the authors. Licensee MDPI, Basel, Switzerland. This article is an open access article distributed under the terms and conditions of the Creative Commons Attribution (CC BY) license (http:/ / creativecommons.org/licenses/by/4.0/). 